\title{
ANALISIS PELEPASAN BEBAN (LOAD SHEDDING) MENGGUNAKAN UNDER FREQUENCY RELAY PADA PEMBANGKITAN TANJUNG JATI B JEPARA
}

\author{
Tio Vanny Br Karo*), Jaka Windarta dan Mochammad Facta \\ Departemen Teknik Elektro, Universitas Diponegoro \\ Jl. Prof. Sudharto, SH, Kampus UNDIP Tembalang, Semarang 50275, Indonesia \\ ${ }^{*}$ E-mail: tiovannybrkaro@gmail.com
}

\begin{abstract}
Abstrak
Adanya perubahan beban secara tiba-tiba akan mengakibatkan perubahan kestabilaan pada sistem. Salah satunya adalah perubahan kestabilan frekuensi sistem. Frekuensi akan naik apabila pembangkit menghasilkan daya yang lebih besar dari pada permintaan beban dan sebaliknya frekuensi akan turun bila pembangkit menghasilkan daya yang lebih kecil dibandingkan dengan permintaan beban. Apabila penurunan frekuensi tidak segera ditanggulangi makan akan menyebabkan sistem tersebut mengalami pemadaman total (black out). Salah satu tindakan yang harus dilakukan untuk menanggulangi turunnya frekuensi adalah dengan melakukan pelepasan beban (load shedding) yang diharapkan dapat memulihkan frekuensi dengan cepat dan jumlah beban yang dilepaskan seminimal mungkin. Pada Penelitian ini dibuat simulasi pelepasan beban pada Pembangkitan Tanjung Jati B Jepara dan pada daerah Jepara, Kuduss, Sayung, Jekulo, Pati dan Rembang. Simulasi ini digunakan untuk menganalisis frekuensi dan tegangan sistem akibat gangguan yang diberikan pada sistem yaitu gangguan skenario beban 30\%, skenario beban $50 \%$, skenario beban $70 \%$ dan skenario beban $100 \%$. Dari hasil simulasi menggunakan software ETAP 12.6.0 menunjukkan bahwa pada skenario beban 30\%, $50 \%$ dan $70 \%$ tidak dilakukan pelepasan beban karena perubahan frekuensi tidak mencapai frekuensi setting sebesar 98\%. Sedangkan ketika dilakukan skenario beban $100 \%$ dilakukan pelepasan beban sebesar 90 MVA dan dapat mengembalikan frekuensi menjadi normal pada detik ke-48,2.
\end{abstract}

Kata kunci: Pelepasan beban, Penurunan Frekuensi, Metode under frequency relay, software ETAP 12.6.0

\begin{abstract}
The load changes suddenly will cause changes in the stability of the system. One of them is the change of system frequency stability. The frequency will increase if the generator produces larger power than the load demand and vice versa. If the decrease in frequency is not immediately addressed, it will cause a blackout system. One of the actions that must be done to overcome the frequency down is the load shedding. It is expected to return the frequency back shortly with the minimum load shedded. In this work, the simulation of load shedding at Pembangkitan Tanjung Jati B Jepara and area Jepara, Kudus, Sayung, Jekulo, Pati and Rembang is made. This simulation is conducted to analyze the frequency and voltage of the system The load variation given to the system those load variation are set up in $30 \%$ load scenario, 50\%, 70\% and 100\%. The results of ETAP 12.6.0 software simulation shows that in 30\%, 50\% and 70\% load scenario caused no load shedding because the change of frequency do not reach the setting frequency of $98 \%$. In $100 \%$ load scenario, 60 MVA load shedding can return the frequency back to normal in 27 seconds.
\end{abstract}

Keywords: Load Shedding, decrease in frequency, under frequency relay method, software ETAP 12.6.0

\section{Pendahuluan}

Sistem tenaga listrik merupakan kesatuan dari beberapa sistem yaitu sistem pembangkit tenaga listrik, sistem transmisi tenaga listrik, sistem distribusi tenaga listrik, serta terdapat sistem proteksi yang melindungi sistem dari gangguan [1]. Jika pada salah satu sistem terjadi gangguan, maka akan berakibat pada kestabilan seluruh sistem. Kestabilan frekuensi adalah kemampuan suatu sistem tenaga untuk menjaga frekuensi dalam batas nominal setelah terjadi suatu gangguan yang menyebabkan ketidakseimbangan yang signifikan antara pembangkitan dan beban [1].

Ketidakstabilan frekuensi seperti penurunan frekuensi yang drastis dapat menyebabkan sistem mengalami pemadaman total (black out). Untuk menjaga agar nilai frekuensi selalu pada batas yang diizinkan, maka diperlukan tindakan untuk mengembalikan frekuensi menjadi normal yaitu dengan melakukan pelepasan beban (load shedding). Salah satu metode yang dapat dilakukan 
adalah dengan menggunakan metode under frequency relay.

Oleh karena itu, penulis melakukan Analisis Pelepasan Beban (Load Shedding) menggunakan Under Frequency Relay pada Pembangkitan Tanjung Jati B Jepara. Penggunaan under frequency relay diharapkan dapat mengoptimalkan penentuan prioritas beban yang akan dilepas oleh pembangkit dengan memperhatikan kecepatan pemulihan frekuensi dengan pelepasan beban tersebut.

\section{Metode}

\subsection{Langkah Penelitian}

Pada penelitian ini terdapat beberapa tahapan yang dilakukan dalam melakukan penelitian. Berikut ini langkah-langkah penelitian yang dapat dilihat pada Gambar 1.

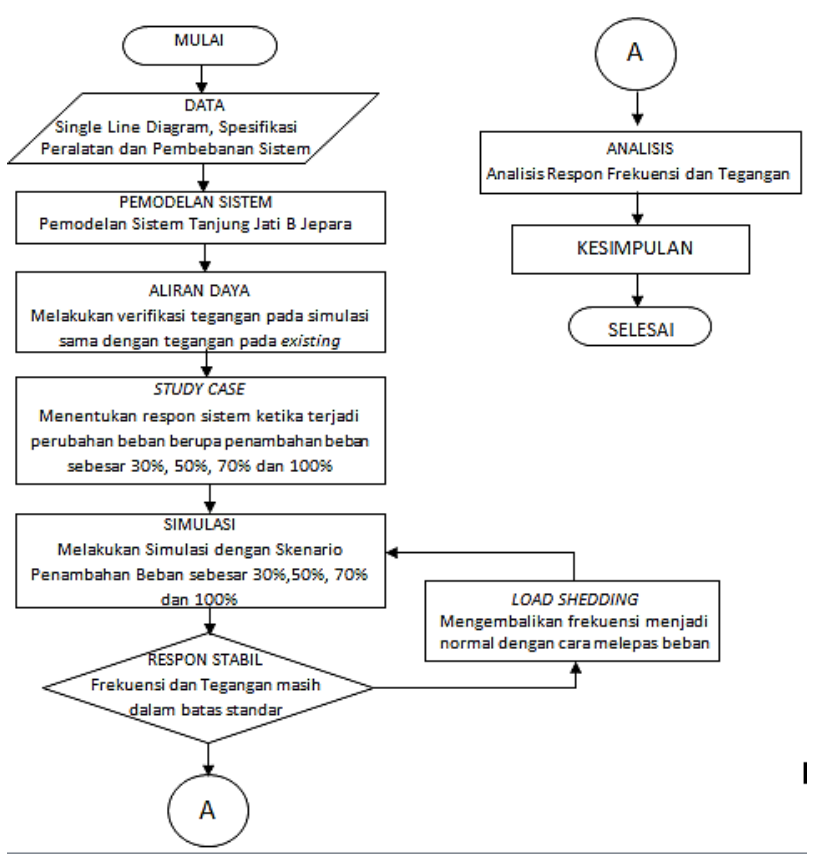

\section{Gambar 1. Diagram Langkah Penelitian}

Gambar 1 menjelaskan tentang proses pemodelan sistem Pembangkitan Tanjung Jati B Jepara pada software ETAP yang sudah sesuai dengan kondisi exsiting berdasarkan aliran daya. Setelah itu dilakukan investigasi dengan cara penambahan beban untuk mengetahui respon yang terjadi pada sistem. Respon sistem yang diamati adalah respon frekuensi dan respon tegangan dengan penambahan beban yang dilakukan sebesar 30\%, 50\%, $70 \%$ dan $100 \%$. Ketika terjadi penurunan frekuensi yang sangat signifikan dibawah 98\%. Maka akan dilakukan pelepasan beban secara otomatis dengan menggunakan under frequency relay yang bekerja untuk membuka circuit breaker yang menghubungkan beban dengan sistem pembangkitan sehingga penurunan frekuensi tersebut dapat kembali naik menjadi normal.

\subsection{Data Penelitian}

Data-data yang digunakan diperoleh dari Pembangkitan Tanjung Jati B Jepara dan APB Ungaran. Data-data yang diperoleh antara lain sebagai berikut.

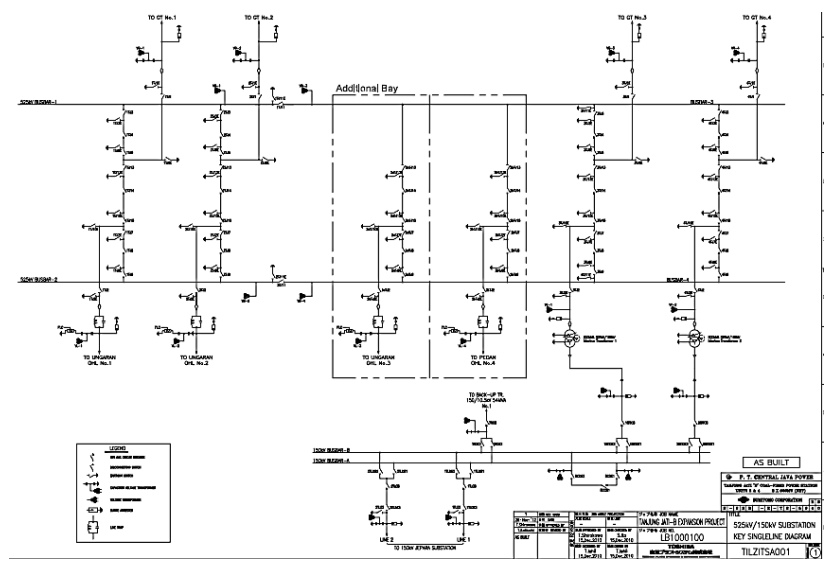

Gambar 2. Single Line Diagram TJB

Gambar 2 merupakan Single line diagram Pembangkitan Tanjung Jati B Jepara. PLTU Tanjung Jati B Jepara disuplai oleh empat generator dengan keluaran netto masing-masing generator sebesar 721,8 MW dan keluaran net masing-masing generator sebesar 660 MW. Dan memiliki empat trafo step-up dengan kapasitas masingmasing trafo sebesar 786 MVA. TJB juga memiliki dua trafo step down dengan masing-masing kapasitas sebesar 500 MVA.

Tabel 1. Spesifikasi Generator PLTU Tanjung Jati B Jepara

\begin{tabular}{cc}
\hline Parameter & Spesifikasi \\
\hline Merk & Toshiba \\
Type & Sinkron, $3 \varphi$ \\
Daya aktif & $721.8 \mathrm{MW}$ \\
Daya nyata & $802 \mathrm{MVA}$ \\
Tegangan & $22.8 \mathrm{kV}$ \\
Power Factor & 0,9 \\
Frekuensi & $50 \mathrm{~Hz}$ \\
RPM & $3000 \mathrm{RPM}$ \\
Eksitasi & Static dengan penyearah \\
thyristor \\
Xd" (Reaktansi Substransien) & $0,258 \mathrm{pu}$ \\
Xd' (Reaktansi Transien) & $0,327 \mathrm{pu}$ \\
Xd (Reaktansi urutan positif) & $2,23 \mathrm{pu}$ \\
X & (Reaktansi urutan negatif) \\
Xo (Reaktansi urutan nol) & $0,258 \mathrm{pu}$ \\
Momen Inersia & $0,142 \mathrm{pu}$ \\
\end{tabular}


Tabel 2. Spesifikasi Trafo Step-Up

\begin{tabular}{cc}
\hline Parameter & Spesifikasi \\
\hline Merk & Toshiba \\
Daya Output & $786 \mathrm{MVA}$ \\
Jumlah Fasa & 3 \\
Frekuensi & $50 \mathrm{~Hz}$ \\
Tegangan & $22.8 / 525 \mathrm{kV}$ \\
Connection & Delta / Star \\
Vektor Grup & YNd11 \\
Tipe pendingin & ODAF \\
Grounding & Solid grounding titik netral sisi \\
& tegangan tinggi \\
\hline
\end{tabular}

\subsection{Setting Under Frequency Relay}

Under frequency relay digunakan untuk melepas beban agar frekuensi kembali normal. Berikut Tabel 3 Setting under frequency relay yang digunakan pada penelitian ini. Tabel 3. Setting Under Frequency Relay TJB

\begin{tabular}{cccc}
\hline $\begin{array}{c}\text { Frek Set } \\
(\%)\end{array}$ & Circuit Breaker & Action & Time Delay \\
\hline 98 & CB41 & Open & 0,1 \\
\hline
\end{tabular}

\subsection{Perancangan Skenario Gangguan}

Skenario penambahan beban yang dilakukan ditunjukkan pada Tabel 4.

Tabel 4. Skenario Penambahan Beban

\begin{tabular}{|c|c|c|c|}
\hline Skenario & $\begin{array}{l}\text { Daya Skenario } \\
\text { (MVA) }\end{array}$ & $\begin{array}{c}\text { Beban yang } \\
\text { dihubungkan }\end{array}$ & $\begin{array}{l}\text { Daya Beban } \\
\text { Trafo (MVA) }\end{array}$ \\
\hline \multirow{4}{*}{$\begin{array}{c}\text { Beban } \\
30 \%\end{array}$} & 240 & Jepara-1 & 60 \\
\hline & & Jepara-2 & 60 \\
\hline & & Kudus-1 & 60 \\
\hline & & Kudus-2 & 60 \\
\hline \multirow{9}{*}{$\begin{array}{c}\text { Beban } \\
50 \%\end{array}$} & 390 & Jepara-1 & 60 \\
\hline & & Jepara-2 & 60 \\
\hline & & Kudus-1 & 60 \\
\hline & & Kudus-2 & 60 \\
\hline & & Kudus-3 & 60 \\
\hline & & Sayung-1 & 30 \\
\hline & & Sayung-2 & 60 \\
\hline & & Jepara-1 & 60 \\
\hline & & Jepara-2 & 60 \\
\hline & & Kudus-1 & 60 \\
\hline \multirow{7}{*}{$\begin{array}{c}\text { Beban } \\
70 \%\end{array}$} & 540 & Kudus-2 & 60 \\
\hline & & Kudus-3 & 60 \\
\hline & & Sayung-1 & 30 \\
\hline & & Sayung-2 & 60 \\
\hline & & Sayung-3 & 60 \\
\hline & & Jekulo-1 & 60 \\
\hline & & Jekulo-2 & 30 \\
\hline \multirow{8}{*}{$\begin{array}{l}\text { Beban } \\
100 \%\end{array}$} & 780 & Jepara-1 & 60 \\
\hline & & Jepara-2 & 60 \\
\hline & & Kudus-1 & 60 \\
\hline & & Kudus-2 & 60 \\
\hline & & Kudus-3 & 60 \\
\hline & & Sayung-1 & 30 \\
\hline & & Sayung-2 & 60 \\
\hline & & Sayung-3 & 60 \\
\hline \multirow{6}{*}{$\begin{array}{l}\text { Beban } \\
100 \%\end{array}$} & 780 & Jekulo-1 & 60 \\
\hline & & Jekulo-2 & 30 \\
\hline & & Pati-1 & 60 \\
\hline & & Pati-2 & 60 \\
\hline & & Pati-3 & 60 \\
\hline & & Rembang-1 & 60 \\
\hline
\end{tabular}

\subsection{Simulasi Aliran Daya}

Pada penelitian ini, simulasi aliran daya digunakan untuk mengetahui tegangan pangkal pada jaringan PLTU Tanjung Jati B sudah sesuai dengan Standar PLN 1:1995. Pada SPLN 1:1995 ini dijelaskan bahwa variasi tegangan ditetapkan maksimum $+5 \%$ dan minimum $-10 \%$ terhadap tegangan nominalnya. Berikut hasil simulasi aliran daya yang dilakukan.

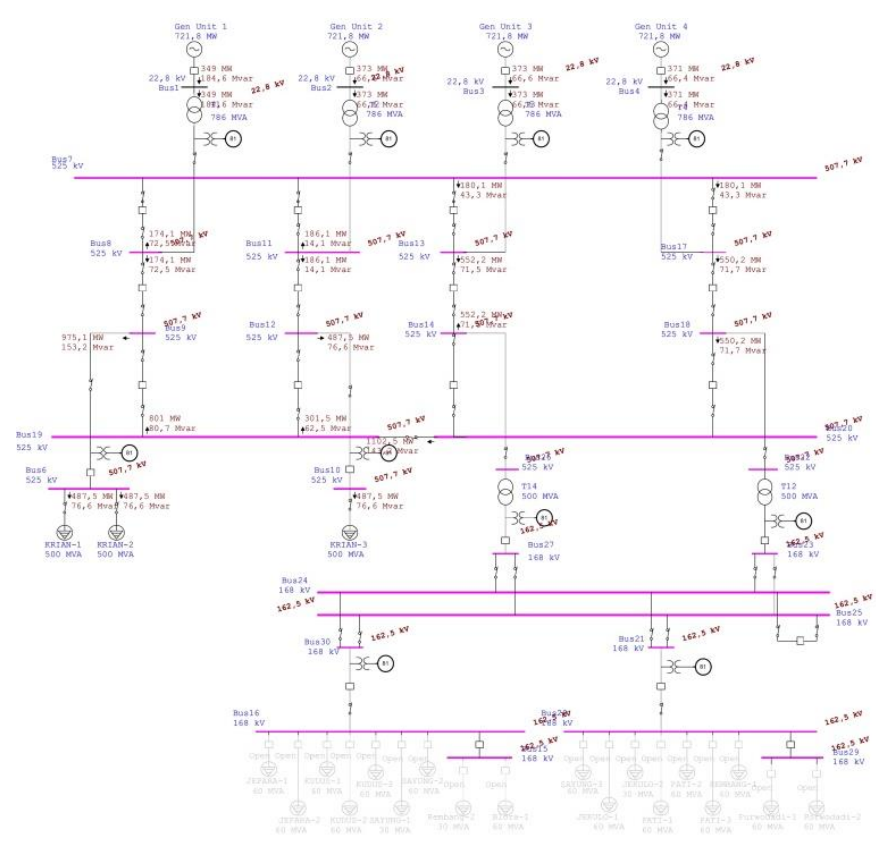

Gambar 3. Hasil Simulasi Aliran Daya Sistem Jaringan Pembangkitan Tanjung Jati B Jepara

Pada kondisi existing memiliki beban sebesar 2279,81 MW dan beban perancangan pada simulasi sebesar 2280 MW, serta tegangan pangkal bus utama pada kondisi existing sebesar $507 \mathrm{KV}$ dan tegangan pangkal bus utama pada simulasi sebesar 507,3 KV. Sehingga dapat dilihat tegangan pangkal bus utama pada hasil simulasi sudah mendekati tegangan pangkal bus utama pada kondisi existing. Dengan demikian perancangan dan konfigurasi jaringan sudah sesuai.

\section{Hasil dan Analisa \\ 3.1. Simulasi Skenario Beban}

Dalam mengamati perubahan respon sistem tenaga listrik, setiap simulasi dijalankan selama 60 detik. Hal yang diamati adalah respon tegangan dan frekuensi pada bus utama yaitu bus7 saat kondisi beban ringan menjadi beban maksimal.

\subsubsection{Respon Tegangan}

Pada semua simulasi skenario penambahan beban terjadi penurunan tegangan. Berikut salah satu hasil simulasi penambahan beban sebesar $30 \%$ setara dengan 240 MVA. 
TRANSIENT, VOL. 7, NO. 1, MARET 2018, ISSN: 2302-9927, 141

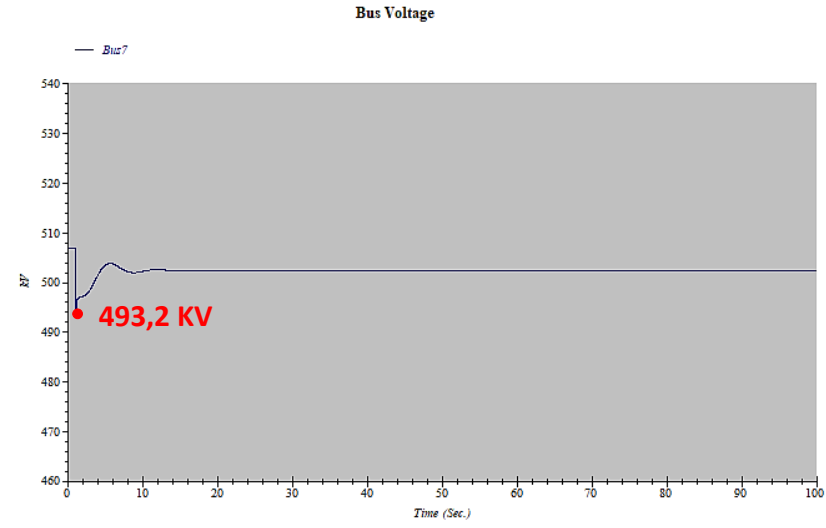

Gambar 4. Contoh Respon Tegangan Skenario Beban 30\%

Pada Gambar 4 tejadi penurunan tegangan dari kondisi awal 506,9 KV menjadi 493,2 KV. Pada skenario penambahan beban $50 \%, 70 \%$ dan $100 \%$ penurunan tegangan menjadi $482,5 \mathrm{KV}, 472,5 \mathrm{KV}$ dan 452,5 KV.

\subsubsection{Respon Frekuensi}

1. Skenario Beban $30 \%$

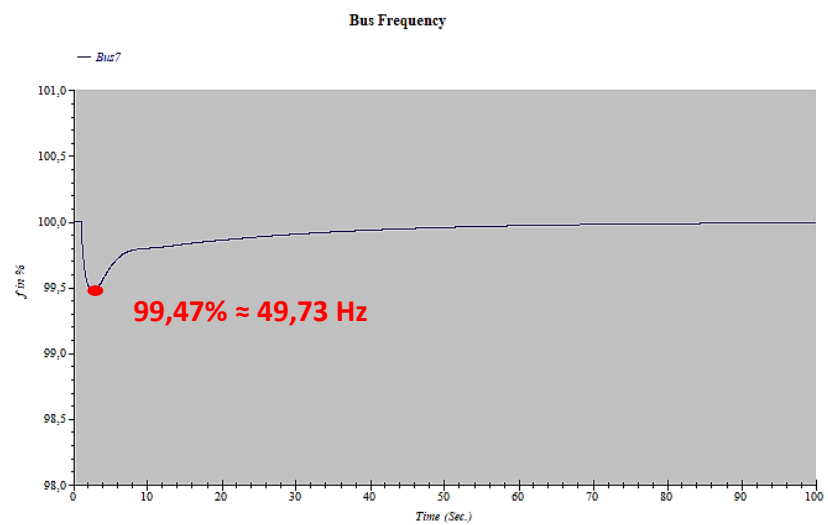

Gambar 5. Respon Frekuensi Bus Utama pada Skenario Beban 30\%

Gambar 5 menunjukkan bahwa ketika beban sebesar 30\% dihubungkan ke jaringan $150 \mathrm{KV}$ Pembangkitan Tanjung Jati B, maka akan mengakibatkan penurunan frekuensi pada detik ke-2,5 dari kondisi awal yaitu $100 \%$ dengan nilai frekuensi sebesar $50 \mathrm{~Hz}$ menjadi 99,47\% dengan nilai frekuensi sebesar 49,73 Hz. Hal ini diakibatkan oleh adanya permintaan daya yang besar yaitu 240 MVA pada sistem jaringan $150 \mathrm{KV}$ PLTU Tanjung Jati B. Besar laju penurunan frekuensi sistem ini adalah $0,18 \mathrm{~Hz} /$ detik.
2. Skenario Beban $50 \%$

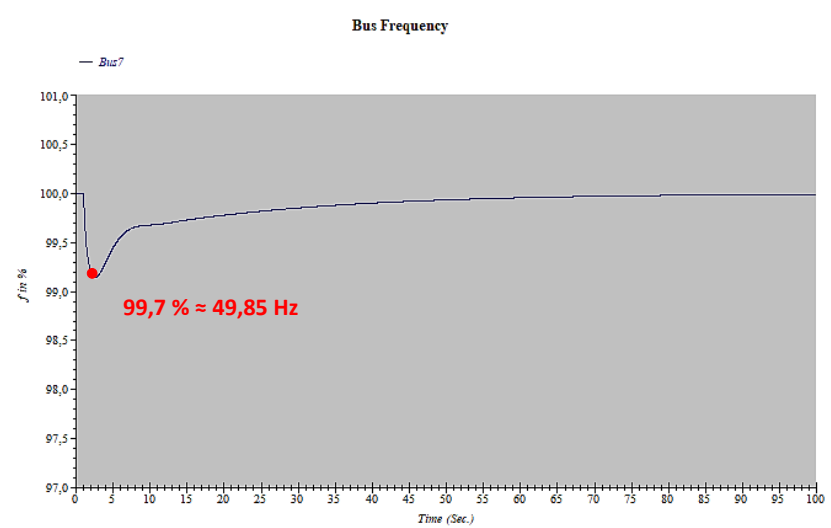

Gambar 6. Respon Frekuensi Bus Utama pada Skenario Beban 50\%

Gambar 6 menunjukkan bahwa ketika beban sebesar 50\% dihubungkan ke jaringan $150 \mathrm{KV}$ PLTU Tanjung Jati B, maka akan mengakibatkan penurunan frekuensi pada detik ke-2,5 dari kondisi awal 100\% dengan besar nilai frekuensi $50 \mathrm{~Hz}$ menjadi 99,7\% setara dengan 49,85 Hz. Hal ini diakibatkan oleh adanya permintaan daya yang besar yaitu 390 MVA pada sistem jaringan 150 KV PLTU Tanjung Jati B. Besar laju penurunan frekuensi sistem ini adalah $0,28 \mathrm{~Hz} /$ detik.

\section{Skenario Beban $70 \%$}

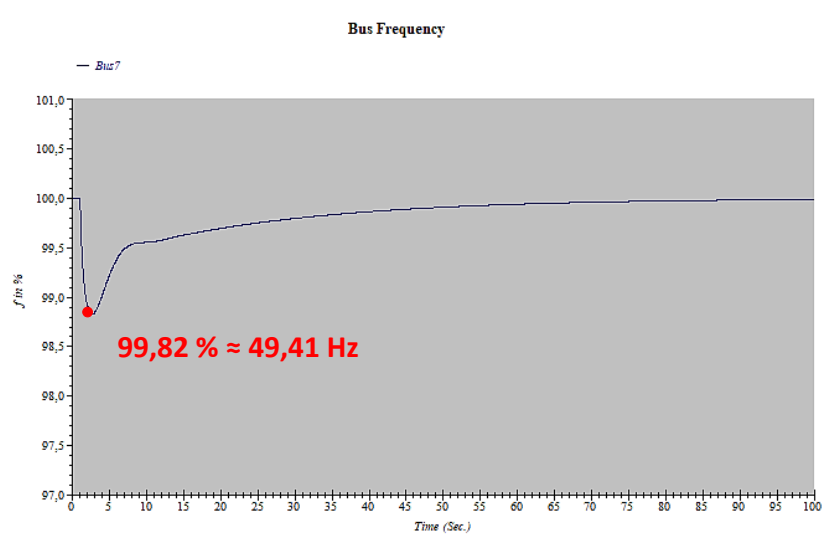

Gambar 7. Respon Frekuensi Bus Utama pada Skenario Beban 70\%

Gambar 7 menunjukkan bahwa ketika beban sebesar $70 \%$ dihubungkan ke jaringan $150 \mathrm{KV}$ PLTU Tanjung Jati B, maka akan mengakibatkan penurunan frekuensi pada detik ke-2,5 dari kondisi awal 100\% dengan besar nilai frekuensi $50 \mathrm{~Hz}$ menjadi 99,82\% setara dengan 49,41 Hz. Hal ini diakibatkan oleh adanya permintaan daya yang besar yaitu 540 MVA pada sistem jaringan $150 \mathrm{KV}$ PLTU Tanjung Jati B. Besar laju penurunan frekuensi sistem ini adalah $0,39 \mathrm{~Hz} /$ detik. 
4. Skenario Beban $100 \%$

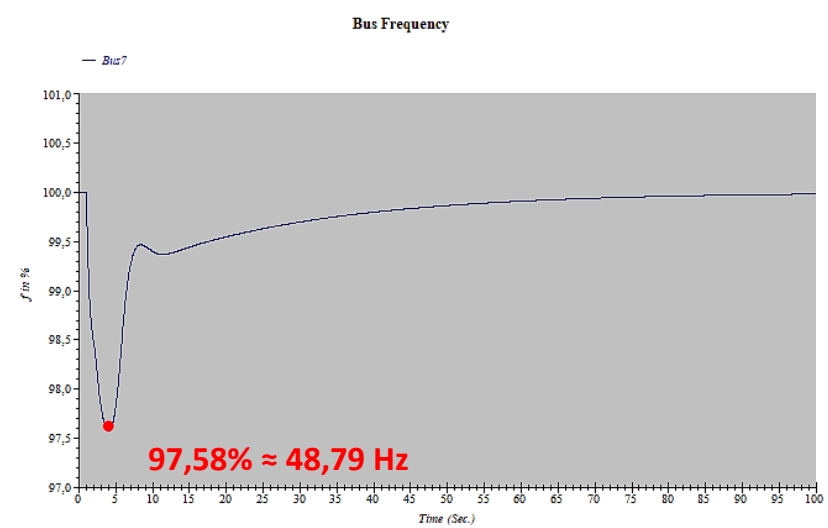

Gambar 8. Respon Frekuensi Bus Utama pada Skenario Beban 100\%

Gambar 8 menunjukkan bahwa ketika beban sebesar 100\% dihubungkan ke jaringan $150 \mathrm{KV}$ PLTU Tanjung Jati B, maka akan mengakibatkan penurunan frekuensi pada detik ke-4 dari kondisi awal 100\% setara dengan 50 $\mathrm{Hz}$ menjadi $97,58 \%$ setara dengan $48,79 \mathrm{~Hz}$. Hal ini diakibatkan oleh adanya permintaan daya yang besar yaitu 780 MVA pada sistem jaringan $150 \mathrm{KV}$ PLTU Tanjung Jati B. Besar laju penurunan frekuensi sistem ini adalah $0,40 \mathrm{~Hz} /$ detik.

\subsection{Simulasi Pelepasan Beban}

Pada simulasi pelepasan beban ini digunakan UFR untuk melepas beban dari sistem agar frekuensi menjadi normal kembali akibat skenario beban yang diberikan.

\subsubsection{Pelepasan Beban pada Skenario Beban $30 \%$}

Setelah dilakukan skenario beban $30 \%$, maka akan mengakibatkan kenaikan frekuensi dari kondisi awal 50 $\mathrm{Hz}$ menjadi 50,4 Hz. Pada penelitian ini menggunakan under frequency relay dimana frekuensi pada skenario beban $30 \%$ tidak di respon oleh rele. Hal ini disebabkan karena pada skenario beban $30 \%$ tidak terjadi penurunan frekuensi melainkan naiknya frekuensi dari kondisi normal. Under frequency relay pada sistem PLTU Tanjung Jati B di settting 98\% dengan nilai frekuensi 49 Hz. Pada simulasi ini kenaikan frekuensi disebabkan oleh adanya penurunan permintaan daya aktif pada jaringan $150 \mathrm{KV}$.

\subsubsection{Pelepasan Beban pada Skenario Beban $50 \%$}

Setelah dilakukan skenario beban $50 \%$, frekuensi akan naik menjadi $50,41 \mathrm{~Hz}$. Under frequency relay tidak merespon penurunan frekuensi pada skenario ini, hal ini disebabkan oleh frekuensi yang dihasilkan tidak mencapai setting dari relay. Under frequency relay pada sistem
PLTU Tanjung Jati B di settting 98\% dengan nilai frekuensi $49 \mathrm{~Hz}$. Penurunan frekuensi disebabkan oleh adanya tambahan permintaan daya aktif pada jaringan 150 $\mathrm{KV}$ dari kondisi beban ringan.

\subsubsection{Pelepasan Beban pada Skenario Beban $70 \%$}

Setelah dilakukan skenario beban $70 \%$ maka akan menghasilkan penurunan frekuensi dari kondisi awal 50 $\mathrm{Hz}$ menjadi 49,41 Hz. Tetapi under frequency relay tidak dapat bekerja karena penurunan frekuensi yang dihasilkan tidak mencapai setting dari relay. . Under frequency relay pada sistem PLTU Tanjung Jati B di settting 98\% dengan nilai frekuensi $49 \mathrm{~Hz}$. Penurunan frekuensi disebabkan oleh adanya tambahan permintaan daya aktif pada jaringan $150 \mathrm{KV}$ dari kondisi beban ringan.

\subsubsection{Pelepasan Beban pada Skenario Beban $100 \%$}

Ketika beban sebesar $100 \%$ dihubungkan ke sistem, maka akan mengakibatkan penurunan frekuensi pada detik ke6,5 menjadi 96,95\% dengan besar nilai frekuensi 48,48 Hz. Oleh karena itu, harus dilakukan pelepasan beban agar frekuensi dapat kembali normal.

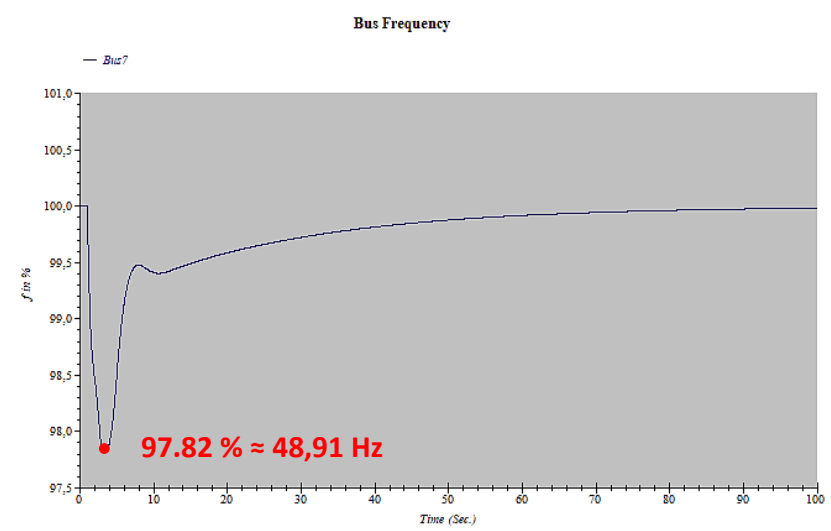

Gambar 9. Respon Frekuensi Pelepasan Beban 60 MVA

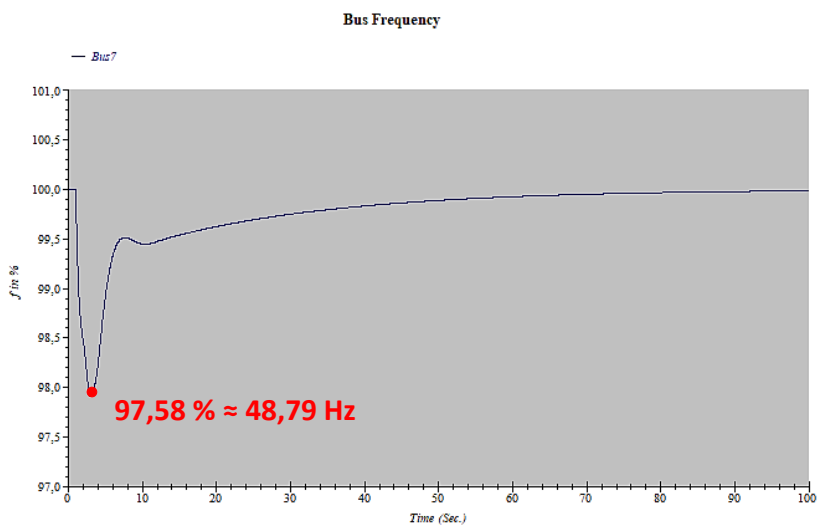

Gambar 10. Respon Frekuensi Pelepasan Beban 120 MVA 
TRANSIENT, VOL. 7, NO. 1, MARET 2018, ISSN: 2302-9927, 143

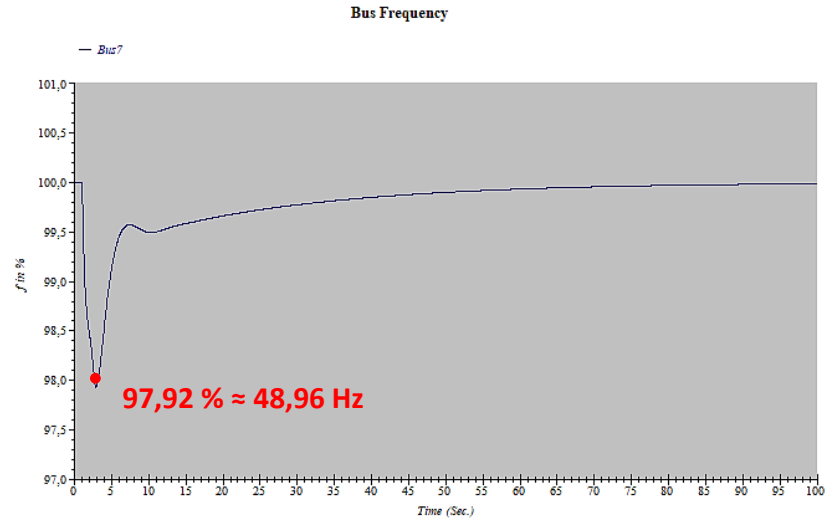

Gambar 11. Respon Frekuensi Pelepasan Beban 180 MVA

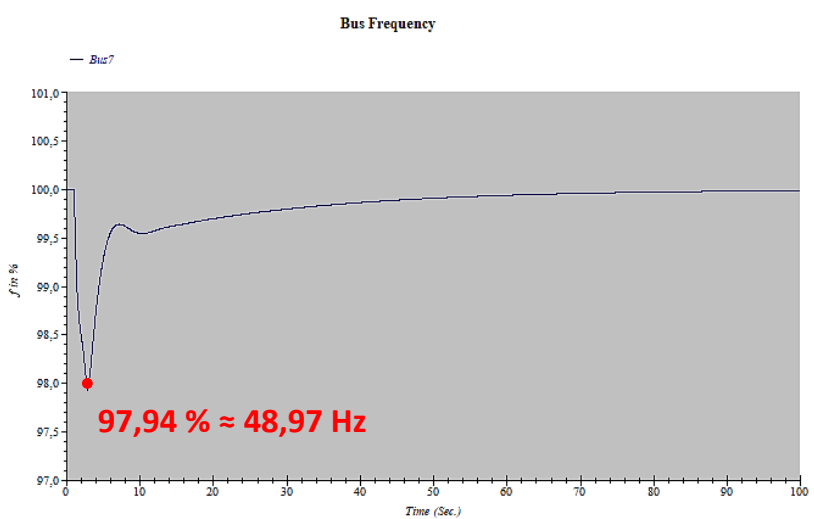

Gambar 12. Respon Frekuensi Pelepasan Beban 240 MVA

Pada Gambar 9 merupakan respon frekuensi bus utama pada saat dilakukan simulasi pelepasan beban sebesar 60 MVA. Dapat dilihat bahwa ketika frekuensi turun hingga mencapai $97,82 \%$ setara dengan 48,91 pada detik ke-3,5, under frequency relay bekerja untuk menaikkan kembali frekuensi agar normal dengan cara melepas beban sebanyak 60 MVA yaitu Jepara-1sebesar 60 MVA sehingga frekuensi dapat kembali normal pada detik ke27 dan stabil pada detik ke-93,5.

Pada Gambar 10 merupakan respon frekuensi saat dilakukan simulasi pelepasan beban sebesar 120 MVA. Dapat dilihat bahwa ketika frekuensi turun hingga mencapai $97,58 \%$ pada detik ke-3. Setelah itu under frequency relay bekerja untuk menaikkan kembali frekuensi agar menjadi normal dengan cara melepas beban sebanyak 120 MVA yaitu Jepara-1 sebesar 60 MVA dan Jepara-2 sebesar 60 MVA sehingga frekuensi dapat kembali normal pada detik ke-25 dan stabil pada detik ke-92.

Pada Gambar 11 merupakan respon frekuensi bus utama pada saat dilakukan simulasi pelepasan beban sebesar 180 MVA. Dapat dilihat bahwa frekuensi turun hingga mencapai $97,92 \%$ setara dengan $48,96 \mathrm{~Hz}$ pada detik ke3. Setelah itu under frequency relay bekerja untuk menaikkan kembali frekuensi agar kembali normal dengan cara melepas beban sebanyak 180 MVA yaitu Jepara-1 sebesar 60 MVA, Jepara-2 sebesar 60 MVA, Kudus-1 sebesar 60 MVA dan Kudus-1 sebesar 60 MVA sehingga frekuensi dapat kembali normal menjadi pada detik ke-22 dan stabil pada detik ke-89,5.

Pada Gambar 12 merupakan pelepasan beban sebesar 240 MVA. Dapat dilihat bahwa frekuensi turun hingga mencapai $97,94 \%$ setara dengan $78,97 \mathrm{~Hz}$ pada detik ke3. Setelah itu under frequency relay bekerja untuk menaikkan kembali frekuensi agar kembali normal dengan cara melepas beban sebanyak 240 MVA yaitu Jepara-1 sebesar 60 MVA, Jepara-2 sebesar 60 MVA, dan Kudus-1 sebesar 60 MVA dan Kudus-2 sebesar 60 MVA sehingga frekuensi dapat kembali normal pada detik ke19 dan stabil pada detik ke-83.

Dari keempat percobaan pelepasan beban tersebut, dapat dilihat ketika beban yang dilepaskan semakin besar maka waktu pemulihan frekuensi akan semakin cepat.

Berikut ini Tabel 5 pelepasan beban yang dilakukan pada sistem jaringan Jateng dan DIY dengan menggunakan under frequency relay.

Tabel 5. Operasi Under Frequency Relay pada Sistem Jaringan Jateng dan DIY

\begin{tabular}{|c|c|c|c|c|c|c|}
\hline \multicolumn{2}{|c|}{ UFR ( Hz ) } & \multicolumn{3}{|c|}{ Lokasi } & \multirow{2}{*}{$\begin{array}{c}\text { Beban } \\
\text { Siang }\end{array}$} & \multirow{2}{*}{$\begin{array}{l}\text { Beban } \\
\text { Malam }\end{array}$} \\
\hline Tahap & Set & GI & Trafo & Peny & & \\
\hline \multirow[t]{26}{*}{$\begin{array}{c}\text { Tahap } \\
4\end{array}$} & \multirow[t]{26}{*}{48,7} & SYUNG & 1 & SYG 3 & 11,30 & 6,50 \\
\hline & & RDRUT & 1 & RDT.3 & 7,00 & 5,00 \\
\hline & & RDRUT & 2 & RDT.9 & 2,60 & 1,50 \\
\hline & & BSBRU & 2 & BSB.4 & 7,20 & 8,70 \\
\hline & & BLORA & 2 & BLA.1 & 5,50 & 11,00 \\
\hline & & TJATI & 1 & TJB.2 & 5,40 & 9,80 \\
\hline & & BLORA & 1 & BLA 3 & 2,50 & 4,10 \\
\hline & & MNANG & 2 & MJG 5 & 4,80 & 5,90 \\
\hline & & GBONG & 2 & GBG 6 & 3,20 & 4,00 \\
\hline & & MRICA & 2 & MRA.2 & 4,20 & 7,70 \\
\hline & & BRBES & 1 & BBS. 5 & 4,60 & 7,20 \\
\hline & & PMLNG & 1 & PML 3 & 8,10 & 9,20 \\
\hline & & BTANG & 2 & BTG.8 & 4,10 & 6,20 \\
\hline & & KSGHN & 1 & KSG 5 & 0,00 & 0,00 \\
\hline & & WDLTG & 1 & WDL 3 & 1,70 & 2,50 \\
\hline & & BTANG & 2 & BTG 1 & 5,80 & 4,00 \\
\hline & & SRAGN & 3 & SRN 1 & 6,10 & 7,40 \\
\hline & & WSARI & 1 & WSI.9 & 8,00 & 10,90 \\
\hline & & WNGRI & 1 & WNI.1 & 0,00 & 10,77 \\
\hline & & MJNGO & 1 & MJO 2 & 8,80 & 10,60 \\
\hline & & KNTUG & 2 & KTN 1 & 7,90 & 8,40 \\
\hline & & SMANU & 1 & SMU 5 & 5,70 & 7,10 \\
\hline & & WATES & 4 & WTS 4 & 3,80 & 11,00 \\
\hline & & PWRJO & 5 & PWO 5 & 4,10 & 5,70 \\
\hline & & TMGNG & 1 & TMG 3 & 6,80 & 9,00 \\
\hline & & BRNGI & 2 & BRG.5 & 5,00 & 7,00 \\
\hline Total & & & 26 & 134,2 & 181,17 & \\
\hline
\end{tabular}

Pada Tabel 5 beban yang dilepaskan untuk mengembalikan frekuensi menjadi normal sebesar 134,10 MW ketika beban siang dan 181,17 MW pada saat beban 


\section{TRANSIENT, VOL. 7, NO. 1, MARET 2018, ISSN: 2302-9927, 144}

malam dengan jumlah penyulang yang di lepas 26 penyulang. Ketika penurunan frekuensi mencapai 97,46\% pada Pembangkitan Tanjung Jati B, penulis melakukan pelepasan beban sebesar $90 \mathrm{MVA}$ atau $81 \mathrm{MW}$. Pada pelepasan beban sebesar $81 \mathrm{MW}$ tersebut frekuensi dapat kembali normal membutuhkan waktu selama 47 detik. Jika dibandingkan dengan pelepasan beban Jateng dan DIY, beban yang paling sedikit dilepas adalah pelepasan beban yang dilakukan oleh penulis. Dari sisi produsen listrik yaitu Pembangkitan Tanjung Jati B, semakin besar pelepasan beban maka keuntungan yang dihasilkan akan semakin sedikit. Oleh karena itu, semakin sedikit pelepasan beban yang dilakukan maka Pembangkitan Tanjung Jati B akan mengalami keuntungan yang semakin besar.

\subsection{Rekonfigurasi Setting Under Frequency Relay yang Baru dan Hasil Simulasi}

Berikut rekonfigurasi setting under frequency relay yang baru pada percobaan pelepasan beban yang telah dilakukan tersebut.

Tabel 6. Rekonfigurasi Setting Under Frequency Relay yang Baru

\begin{tabular}{ccccc}
\hline $\begin{array}{c}\text { Set Frek } \\
(\mathrm{Hz})\end{array}$ & $\begin{array}{c}\text { Time Delay } \\
\text { (detik) }\end{array}$ & $\begin{array}{c}\text { Open } \\
\text { Circuit } \\
\text { Breaker }\end{array}$ & Penyulang & $\begin{array}{c}\text { Beban } \\
\text { yang } \\
\text { Dilepas } \\
\text { (MVA) }\end{array}$ \\
\hline $98 \%$ & 0,1 & CB27 & Jepara-1 & 60 \\
\hline
\end{tabular}

Tabel 6 menunjukkan bahwa setting frequency yang digunakan pada UFR tersebut sebesar $98 \% \mathrm{~Hz}$ dengan frekuensi sebesar 49,0 Hz dan Time delay sebesar 0,1 detik. Circuit breaker yang dikendalikan oleh under frequency relay ini adalah CB27. Dimana CB27 ini terhubung dengan dengan penyulang Jepara-1 dengan beban trafo 60 MVA. Berikut Gambar 13 hasil simulasi pelepasan beban sebesar 60 MVA yang telah dilakukan.

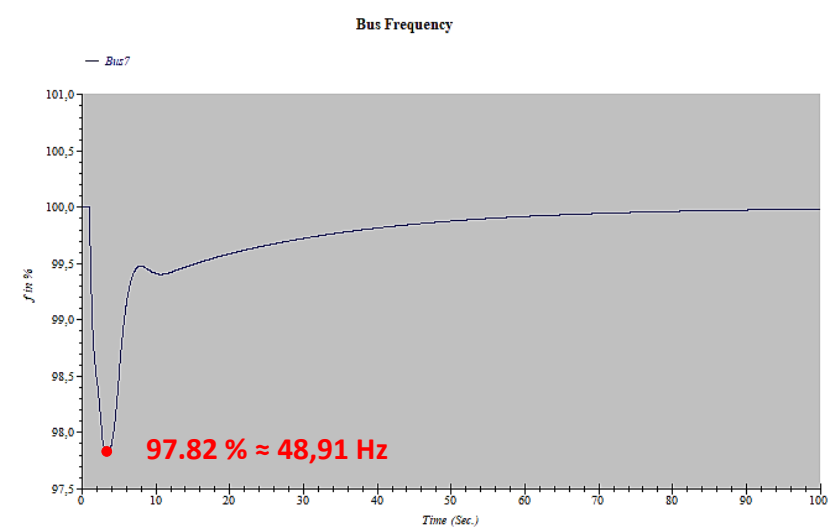

Gambar 13 Respon Frekuensi Pelepasan Beban 60 MVA

Pada Gambar 13 dapat dilihat bahwa under frequency relay ini membutuhkan waktu selama 27 detik untuk mengembalikan penurunan frekuensi akibat skenario penambahan beban $100 \%$ menjadi normal.

\section{Kesimpulan}

Berdasarkan simulasi dan analisis yang telah dilakukan, maka dapat disimpulkan bahwa respon frekuensi sistem yang terhubung dengan Pembangkitan Tanjung Jati B Jepara telah dapatdilakukan simulasinya dan dapat diamati perilaku stabilitas frekuensinya dengan menggunakan fasilitas Analysis Transient Stability pada ETAP 12.6.0. Pada skenario penambahan beban $30 \%$ dan $50 \%$ sistem mengalami penurunan frekuensi yang tidak signifikan yaitu sebesar $49,73 \mathrm{~Hz}$ dan $49,57 \mathrm{~Hz}$ Namun, jika skenario beban sebesar $70 \%$ dan $100 \%$ dilakukan maka sistem akan mengalami penurunan frekuensi yang cukup signifikan yaitu sebesar $49,41 \mathrm{~Hz}$ dan $48,79 \mathrm{~Hz}$. Untuk respon tegangan pada skenario penambahan beban $30 \%$, 50\%, $70 \%$ dan $100 \%$ mengalami penurunan tegangan yaitu sebesar 493,2 KV, 482,5 KV, 472,5 KV dan 452,5 KV. Pada skenario beban 30\%, skenario beban $50 \%$, dan skenario beban $70 \%$ tidak dapat dilakukan pelepasan beban dikarenakan frekuensi yang dihasilkan belum mencapai frekuensi setting dari under frequency relay sebesar $49 \mathrm{~Hz}$. Pada skenario beban $100 \%$ dihasilkan penurunan frekuensi $48,79 \mathrm{~Hz}$ yang mencapai setting frekuensi under frequency relay sebesar $49 \mathrm{~Hz}$. Sehingga dilakukan pelepasan beban sebesar 60 MVA dan dapat mengembalikan frekuensi menjadi normal pada detik ke-27.

\section{Referensi}

[1] Marsudi, Jiteng, Operasi Sistem Tenaga Listrik. Yogyakarta: Graha Ilmu, 2006.

[2] D. Marsudi, Pembangkitan Energi Listrik. Jakarta: Erlangga, 2011.

[3] S. J. Chapman, Electric Machinery Fundamentals, Second. Singapore: Mc Graw Hill Companies, 1991.

[4] H. Saadat, Power System Analysis. The McGraw-Hill Companies Schaum's, 1999.

[5] J. W. J. Machowski, J.R. Bumby, Power System Dynamics and Stability. J. Wiley \& Sons Ltd, 1997.

[6] D. Suswanto, "Sistem Distribusi Tenaga Listrik," pp. 185-200, 2009

[7] R. Ramani, "Perbaikan Skema Pertahanan dengan Koordinasi Rele Frekuensi, Rele Kecuraman Frekuensi dan Operasi Pulau (Studi Kasus Sistem Lampung)," Inst. Teknol. Bandung, 2011.

[8] IEEE Guide for Abnormal Frequency Protection for Power Generating Plants. ANSI/IEEE C37. 106-1987, 2003.

[9] Strategi Tongkat Frekuensi PT. PLN APB Jateng dan DIY. .

[10] ANSI/IEEE Std C37.102-1995.

[11] PT PLN (Persero), Buku Ajar Stabilitass Frekuensi (Frequrency Stability).

[12] Island Operation Sistem Tenaga Listrik Jawa Tengah bulan Maret tahun 2003. 